\title{
Intraoperative hypothermia in patients undergoing Total knee arthroplasty: a cross-sectional study from a developing country
}

Ronika Devi Ukrani ${ }^{1}$, Aiman Arif ${ }^{1 *}$, Anum Sadruddin², Obada Hasan ${ }^{2}$ and Shahryar Noordin ${ }^{2}$

\begin{abstract}
Background: Intraoperative hypothermia is associated with various risk factors, morbidity, and mortality in patients undergoing total knee arthroplasty (TKA), increasing the emotional and financial burden on patients. This study aimed to identify risk factors of intraoperative hypothermia in patients undergoing TKA.
\end{abstract}

Materials and methods: All adult patients ( $\geqslant 18$ years) who underwent TKA from January 2016 to December 2017 at a tertiary-care hospital in Pakistan were included in this retrospective, cross-sectional study. Temperature $<36{ }^{\circ} \mathrm{C}$ was defined as hypothermia.

Results: The study included 286 patients (77.6\% female) with a mean age of $61.4 \pm 10.4$ years. The overall proportion of intraoperative hypothermia was $26.6 \%$. Of the total patients, $66.1 \%$ underwent bilateral TKA whereas $33.9 \%$ underwent unilateral TKA. $73.8 \%$ of the patients were ASA Level 2 . Only $13.3 \%$ of patients had postoperative hypothermia.

Conclusion: Intraoperative hypothermia was significantly associated with age, bilateral procedure, ASA level and postoperative hypothermia in patients undergoing TKA. The surgeon and the operative team should be aware of the risk factors and the adverse outcomes associated with intraoperative hypothermia, especially in resource constrained settings to plan preventive strategies.

Trial registration: This study was retrospectively registered on ClinicalTrials.gov on 3rd October 2020. The registration ID is NCT04575246.

Keywords: Developing country, Hypothermia, Intraoperative hypothermia, SSI, Total knee arthroplasty

\section{Introduction}

Hypothermia, defined as core body temperature $<36^{\circ} \mathrm{C}$ $[1,2]$, is a phenomenon in which the rate of heat loss is greater than the rate of heat production. It results from increased heat redistribution from core to periphery, coupled with decreased metabolic heat production [3].

\footnotetext{
* Correspondence: aimanarif15@gmail.com

${ }^{1}$ Medical College, Aga Khan University Hospital, Karachi 74800, Pakistan Full list of author information is available at the end of the article
}

Intraoperative hypothermia is a common complication of anaesthesia administration that affects normal thermal autoregulation in the body $[4,5]$. Moreover, further heat loss due to the body surface area exposed to the cold operating room environment $[6,7]$ means that normal metabolic heat production is inadequate to maintain the core body temperature of the patient leading to numerous avoidable complications by altering normal physiologic processes in the body. The result of drastic heat loss is systemic vasoconstriction and reduction in

(c) The Author(s). 2021 Open Access This article is licensed under a Creative Commons Attribution 4.0 International License, which permits use, sharing, adaptation, distribution and reproduction in any medium or format, as long as you give appropriate credit to the original author(s) and the source, provide a link to the Creative Commons licence, and indicate if changes were made. The images or other third party material in this article are included in the article's Creative Commons licence, unless indicated otherwise in a credit line to the material. If material is not included in the article's Creative Commons licence and your intended use is not permitted by statutory regulation or exceeds the permitted use, you will need to obtain permission directly from the copyright holder. To view a copy of this licence, visit http://creativecommons.org/licenses/by/4.0/ The Creative Commons Public Domain Dedication waiver (http://creativecommons.org/publicdomain/zero/1.0/) applies to the data made available in this article, unless otherwise stated in a credit line to the data. 
peripheral circulation which leads to several different events such as tissue hypoxia [8], failure of immune cells to reach target cells and altered neutrophil function which are a major cause of post-operative infection $[6,8$, 9]. Other complications include platelet dysfunction leading to bleeding tendencies and increased requirement for blood transfusions [3, 8, 9], and cardiac events such as tachycardia due to increased catecholamine levels causing a detrimental impact on morbidity and mortality of patients $[6,8,9]$. Post-operative shivering can also lead to unnecessary discomfort and prolonged hospitalizations for the patients $[6,8,9]$.

The occurrence of perioperative hypothermia in total joint arthroplasty has been assessed in several studies and has yielded a range of results ranging from 11 to $72 \%[4,10-12]$ to even up to $90 \%$ [7]. A study reported that $34 \%$ of patients undergoing total knee arthroplasty (TKA) have hypothermia at the time of incision and 33\% of the patients stayed hypothermic throughout surgery [7]. Moreover, in the absence of active warming techniques, a $1-2{ }^{\circ} \mathrm{C}$ fall in temperature has been observed in surgical procedures [3].

The increase in the incidence of untoward complications as a result of hypothermia are a cause of concern for patients and surgeons. TKA is a procedure frequently done in elderly patients with end-stage osteoarthritis at our University Hospital. Although previous literature on TKA and hypothermia exists from developed countries, there is a scarcity of data from developing countries for complications hypothermia. The differences in settings, resources and risk factors in developing countries merit further research to enhance the clinical course of these patients. The purpose of this study is to determine the frequency of intraoperative hypothermia and factors associated with intraoperative hypothermia in patients undergoing TKA at a tertiary care hospital in Karachi, Pakistan. This can allow surgical teams in developing countries in the future to determine the risk factors that can be controlled to improve postoperative clinical course with regards to intraoperative hypothermia.

\section{Materials and methods}

\section{Study location and sample}

We conducted a retrospective cross-sectional study of patients who underwent total knee arthroplasty at the Aga Khan University Hospital (AKUH) between the period January 2016 to December 2017. Nonprobability consecutive sampling was used for all patients fulfilling the inclusion criteria which was adults $\geqslant 18$ years undergoing TKA at our University Hospital.

The study was conducted in accordance with the ethical standards described in the 1964 Declaration of Helsinki and its later amendments. Aga Khan University Ethics Review Committee (ERC) approval was obtained prior to the initiation of this study. The ERC study protocol number is 2019-1274-3270. The study was approved with an exemption of informed consent from patients due to lack of contact with them in a retrospective clinical study. Data was collected from patient charts and files without any interaction with the patient.

\section{Patients and methods}

A standardized proforma was used to collect data from an online patient data system about patients' preoperative, intraoperative, and postoperative details. Preoperative data included age, gender, and comorbid conditions. Intraoperative data was collected from the surgical and anaesthesia records and included surgical site, American Society of Anesthesiologists (ASA) Level, duration of surgery, preoperative body temperature, intraoperative body temperature and duration of surgery. Postoperative data included postoperative body temperature and the presence of any surgical site infection within the 1 year follow-up period.

\section{Standard operating conditions}

All TKA procedures at AKUH are conducted under a standard protocol. The operating room temperature is set at $20^{\circ} \mathrm{C}$. Moreover, all patients are given a bear hugger with K-thermia underneath set at $37^{\circ} \mathrm{C}$.

\section{Statistical analysis}

IBM SPSS (Statistical Package for Social Sciences) Version 23.0 was used for all statistical analysis. Continuous data is presented as mean \pm standard deviation with comparison using independent sample t-test. Nominal and ordinal data is presented as $\mathrm{N}(\%)$ with percentages compared using Chi-Square test. A $p$-value of $<0.05$ was considered significant for all analyses.

\section{Results}

The study comprised of a total of 286 patients with $77.6 \%$ of the patients being female. The mean age of the patients was $61.4 \pm 10.4$ years. $64.3 \%$ of the patients were hypertensive and $27.6 \%$ were diabetic. The indication for performing TKA was predominantly osteoarthritis. Of the 286 patients, 189 underwent bilateral TKA, while 97 patients underwent unilateral TKA (right: 46; left: 51). The majority of the patients were classified as ASA Level 2 (73.8\%) followed by ASA Level 3 (20.3\%) and ASA Level 1 (5.9\%). The mean duration of surgery was $201.2 \pm 66.2 \mathrm{~min}$. The mean duration of surgery in patients who underwent unilateral TKA was $131.4 \pm 36.1$ $\mathrm{min}$ as opposed to $237.0 \pm 46.6 \mathrm{~min}$ in patients who had bilateral TKA $(p=0.032)$. Preoperatively, $62(21.7 \%)$ patients had hypothermia. However, 76 (26.6\%) patients developed intraoperative hypothermia while 38 (13.3\%) patients were noted to be hypothermic postoperatively. 
The mean age of patients in the intraoperative hypothermia group was $63.7 \pm 10.1$ years which was significantly higher than the mean age of patients in the normothermia group $(60.5 \pm 10.5$ years; $p=0.023)$. In the intraoperative hypothermia group, $53.9 \%$ of patients underwent bilateral TKA $(p=0.018)$ which was noted to be statistically significant. There were more patients classified as ASA Level 2 in the intraoperative group than in the normothermia group (84.2\% vs. $70.0 \%$; $p=$ 0.049). A significantly lower proportion of intraoperative hypothermia patients had hypothermia postoperatively (23.7\% with $p=0.002$ ). Only 2 patients developed surgical site infection postoperatively.

The results of the study are shown in Table 1 .

\section{Discussion}

The incidence of intraoperative hypothermia in patients undergoing TKA is increasing and is expected to rise to $600 \%$ by 2030 [13]. We conducted a retrospective single centre study to determine risk factors of intraoperative hypothermia in patients undergoing TKA. The results of our study highlight that age, bilateral procedure, ASA level and postoperative hypothermia were significantly associated with intraoperative hypothermia.

The incidence of intraoperative hypothermia reported in our study was $26.6 \%$. The findings of our study are similar to the results of a study conducted by Frisch et al. who reported $32.6 \%$ patients with intraoperative hypothermia during TKA [13].

The mean age of patients in our study was $61.4 \pm 10.4$ years, with intraoperative hypothermia group having a significantly higher age than normothermia group $(p<$ $0.023)$. A previously reported study also had mean age of patients $62 \pm 13$ years which is similar to the finding of our study [14]. Another study conducted in United Kingdom had higher age in hypothermia group compared to normothermia group [2]. Yinan Li et al. also conducted a retrospective study including 1467 patients who underwent video assisted thoracoscopic surgery and reported an increased risk of intraoperative hypothermia with advanced age [15]. Age increases the risk of osteoarthritis and as a result, patients get TKA for management. This association between intraoperative hypothermia and older patients could also be due to decrease in thermoregulatory vasoconstriction threshold in patients under general anaesthesia with age [15].

The percentage of female patients who have had TKA reported in literature vary between approximately 56$74 \%$. Although, the reason for higher prevalence of TKA among females is unclear, the greater percentage of females in our cohort (77.6\%) could be attributed to women being more prone to injuries $[12,13,16,17]$. Female gender is also considered the strongest risk factor for knee osteoarthritis [17].. In addition, female gender is also a risk factor for hypothermia due to smaller reserve of body fat $[7,18]$. The findings of our study show that among the patients in the intraoperative hypothermia group, majority of the patients were female (72.4\%) and only $27.6 \%$ were male. This is also evidenced by the high percentage of $79 \%$ females in the study at AKU Hospital by Usmani et al. [19] The patients in our study had multiple co-morbidities, with hypertension $(64.3 \%)$ being the most common. The prevalence of hypertension in our study is similar to the prevalence of hypertension previously reported in patients undergoing TKA [20].

Majority of the patients in our study had bilateral TKA (66.1\%) and a significantly greater number of patients in intraoperative hypothermia group had bilateral TKA (53.9\%; $p$-value $=0.018)$. Although our findings show that bilateral TKA increased the risk of intraoperative hypothermia compared to a unilateral procedure, there is lack of data showing the correlation of bilateral procedures and intraoperative hypothermia in patients for total knee arthroplasty. Theoretically, in bilateral procedure, the surgical site is exposed to lower temperatures for a total longer duration during sequential surgery, hence there is an increased risk of hypothermia. A study conducted by Qadir et al. reported a higher incidence of sequential bilateral TKA compared to staged TKA in Pakistan [21]. However, more research is required to assess the effect of bilateral TKA on hypothermia.

According to the results of our study, the most common ASA Level was Level 2. In a study conducted by Vural et al. inadvertent hypothermia, in patients from several different fields including orthopedic surgery, was most commonly associated with ASA Level 2 which is consistent with our findings [22]. This study also reported that ASA level had an impact on intraoperative body temperature and was a risk factor of development of hypothermia in univariate analysis [22]. However, in multivariate analysis, ASA Level had no effect on hypothermia [22]. Moreover, studies conducted by Belayneh et al. [23] and Monzón et al. [24] also reported that ASA Level was a risk factor for development of hypothermia. The results of our study reported that ASA Level was significantly associated with intraoperative hypothermia $(p=0.049)$. However, more studies are still required to establish an association between ASA classification and development of intraoperative hypothermia in a developing country.

According to Vural et al., intraoperative hypothermia is a risk factor for postoperative hypothermia [22]. Although our results showed that postoperative hypothermia is significantly associated with intraoperative hypothermia $(p=0.002)$, the incidence of postoperative hypothermia in intraoperative hypothermia group was lower than in 
Table 1 Characteristics of TKA Patients

\begin{tabular}{|c|c|c|c|c|}
\hline \multirow[t]{2}{*}{ Variables } & \multirow{2}{*}{$\begin{array}{l}\text { Overall } \\
(N=286)\end{array}$} & \multicolumn{2}{|c|}{ Intraoperative Hypothermia } & \multirow{2}{*}{$\begin{array}{l}p- \\
\text { value }\end{array}$} \\
\hline & & Yes $(N=76)$ & No $(N=210)$ & \\
\hline Age & $61.4 \pm 10.4$ & $63.7 \pm 10.1$ & $60.5 \pm 10.5$ & 0.023 \\
\hline Gender & & & & 0.200 \\
\hline Male & $64(22.4)$ & $21(27.6)$ & $43(20.5)$ & \\
\hline Female & $222(77.6)$ & $55(72.4)$ & $167(79.5)$ & \\
\hline HTN & & & & 0.418 \\
\hline Yes & $184(64.3)$ & $46(60.5)$ & $138(65.7)$ & \\
\hline No & $102(35.7)$ & $30(39.5)$ & $72(34.3)$ & \\
\hline DM & & & & 0.551 \\
\hline Yes & 79 (27.6) & $19(25.0)$ & $60(28.6)$ & \\
\hline No & $207(72.4)$ & $57(75.0)$ & $150(71.4)$ & \\
\hline \multicolumn{5}{|l|}{ Rheumatoid Arthritis } \\
\hline Yes & $2(0.7)$ & $0(0)$ & $2(1.0)$ & $>0.999$ \\
\hline No & $284(99.3)$ & $76(100)$ & $208(99.0)$ & \\
\hline Osteoarthritis & & & & 0.252 \\
\hline Yes & $9(3.1)$ & $4(5.3)$ & $5(2.4)$ & \\
\hline No & $277(96.9)$ & $72(94.7)$ & $205(97.6)$ & \\
\hline Site & & & & 0.018 \\
\hline Right & $46(16.1)$ & $19(25.0)$ & $27(12.9)$ & \\
\hline Left & $51(17.8)$ & $16(21.1)$ & $35(16.7)$ & \\
\hline Bilateral & $189(66.1)$ & $41(53.9)$ & $148(70.5)$ & \\
\hline ASA Level & & & & 0.049 \\
\hline Level 1 & $17(5.9)$ & $2(2.6)$ & $15(7.1)$ & \\
\hline Level 2 & $211(73.8)$ & $64(84.2)$ & $147(70.0)$ & \\
\hline Level 3 & $58(20.3)$ & $10(13.2)$ & $48(22.9)$ & \\
\hline Preoperative Hypothermia & & & & 0.620 \\
\hline Yes & $62(21.7)$ & $18(23.7)$ & $44(21.1)$ & \\
\hline No & $224(78.3)$ & $58(76.3)$ & $166(79.0)$ & \\
\hline Postoperative Hypothermia & & & & 0.002 \\
\hline Yes & $38(13.3)$ & $18(23.7)$ & $20(9.5)$ & \\
\hline No & $248(86.7)$ & $58(76.3)$ & $190(90.5)$ & \\
\hline SSI & & & & 0.462 \\
\hline Yes & $2(0.7)$ & $1(1.3)$ & $1(0.5)$ & \\
\hline No & $284(99.3)$ & $75(98.7)$ & $209(99.5)$ & \\
\hline Duration of Surgery (mins) & $201.2 \pm 66.2$ & & & \\
\hline Unilateral & $131.4 \pm 36.1$ & $126.4 \pm 38.6$ & $135.2 \pm 33.8$ & 0.2466 \\
\hline Bilateral & $237.0 \pm 46.6$ & $228.3 \pm 49.2$ & $240.4 \pm 45.3$ & 0.1246 \\
\hline
\end{tabular}

normothermia group. The difference in the results can be due to differences in postoperative care.

Only $2(0.7 \%)$ patients developed SSI post-operatively with only 1 (1.3\%) out of total 76 hypothermic patients having suffered infection which was non-significant. Thereby, our study could not find a positive association between intraoperative hypothermia with wound infection, as suggested by other studies [13].

Further studies are required in order to better understand the risk factors associated with hypothermia and its impact on different post-operative outcomes. In addition, further studies can also help devise 
standardized protocols such as effective warming techniques as preventative measures to reduce hypothermia and to reduce the risk of complications that may arise due to it.

\section{Caveats}

There were several limitations in this study. The sample size was small which could be one of the reasons the post-operative hypothermia results were inconsistent with the literature. Body surface area and BMI was not included in the study. Measurement of temperature was not standardized and data on duration of hypothermia and rewarming strategies was also not recorded. ASA Level 4 category patients are not candidates for quality of life surgery and hence were not included which potentially skews the understanding of the association between ASA and hypothermia as the entire spectrum is not included.

\section{Conclusion}

Intraoperative hypothermia is significantly associated with age, bilateral procedures, ASA level and postoperative hypothermia in patients undergoing TKA. The surgeon and the operative team should be aware of the risk factors and the adverse outcomes associated with intraoperative hypothermia, especially in a resource constrained developing country like Pakistan.

\section{Abbreviations}

TKA: Total Knee Arthroplasty; AKUH: Aga Khan University Hospital; ASA Level: American Society of Anesthesiologists (ASA) Level; SSI: Surgical Site Infection; BMI: Body Mass Index; HTN: Hypertension; DM: Diabetes Mellitus

\section{Acknowledgements}

Not applicable.

\section{Authors' contributions}

RDU and AA contributed to the study concept, design, data analysis and manuscript writing. AS was involved in the study concept, design and data analysis. $\mathrm{OH}$ contributed to data collection and analysis. SN contributed to the study concept, design and final approval of the paper. All authors approved the submitted version and have agreed to be personally accountable for their contributions. The authors read and approved the final manuscript.

\section{Funding}

No funding was obtained during this research.

\section{Availability of data and materials}

The datasets generated and/or analysed during the current study are not publicly available since the Ethical Review Committee guidelines do not allow institutional data to be dispersed. However, the data is available on reasonable request to the corresponding author.

\section{Declarations}

\section{Ethics approval and consent to participate}

The study was approved by the Institutional Ethical Review Committee at Aga Khan University Hospital, Karachi with an exemption of informed consent from patients as it is a retrospective study which did not involve any contact with the patient. The reference number for the study was 20191274-3270.
Consent for publication

Not applicable.

\section{Competing interests}

The authors declare that they have no competing interests.

\section{Author details}

${ }^{1}$ Medical College, Aga Khan University Hospital, Karachi 74800, Pakistan. ${ }^{2}$ Department of Orthopaedic Surgery, Aga Khan University Hospital, Karachi 74800, Pakistan.

Received: 2 December 2020 Accepted: 19 May 2021

Published online: 31 May 2021

\section{References}

1. Kleimeyer JP, Harris AHS, Sanford J, Maloney WJ, Kadry B, Bishop JA. Incidence and risk factors for postoperative hypothermia after Orthopaedic surgery. J Am Acad Orthop Surg. 2018;26(24):e497-503. https://doi.org/10. 5435/JAAOS-D-16-00742.

2. Williams $M$, El-Houdiri Y. Inadvertent hypothermia in hip and knee total joint arthroplasty. J Orthop. 2018;15(1):151-8. https://doi.org/10.1016/j.jor.2 018.01.035.

3. Dan M, Martos SM, Beller E, Jones P, Randle R, Liu D. Blood loss in primary total knee arthroplasty--body temperature is not a significant risk factor--a prospective, consecutive, observational cohort study. J Orthop Surg Res. 2015;10(1):97. https://doi.org/10.1186/s13018-015-0241-5.

4. Aksu C, Kuş A, Gürkan Y, Solak M, Toker K. Survey on postoperative hypothermia incidence In operating theatres of Kocaeli University. Turk J Anaesthesiol Reanim. 2014;42(2):66-70. https://doi.org/10.5152/TJAR.2 014.15010.

5. Yi J, Xiang Z, Deng X, Fan T, Fu R, Geng W, et al. Incidence of inadvertent intraoperative hypothermia and its risk factors in patients undergoing general anesthesia in Beijing: a prospective regional survey. PLoS One. 2015: 10(9):e0136136. https://doi.org/10.1371/journal.pone.0136136.

6. Madrid E, Urrútia G, Roqué i Figuls M, Pardo-Hernandez H, Campos JM, Paniagua $P$, et al. Active body surface warming systems for preventing complications caused by inadvertent perioperative hypothermia in adults. Cochrane Database Syst Rev. 2016;4:Cd009016.

7. Simpson JB, Thomas VS, Ismaily SK, Muradov PI, Noble PC, Incavo SJ. Hypothermia in Total joint arthroplasty: a wake-up call. J Arthroplast. 2018. 33(4):1012-8. https://doi.org/10.1016/j.arth.2017.10.057.

8. Giuliano KK, Hendricks J. Inadvertent perioperative hypothermia: current nursing knowledge. AORN J. 2017;105(5):453-63. https://doi.org/10.1016/j.a orn.2017.03.003.

9. Leslie K, Sessler DI. Perioperative hypothermia in the high-risk surgical patient. Best Pract Res Clin Anaesthesiol. 2003;17(4):485-98. https://doi.org/1 0.1016/S1521-6896(03)00049-1.

10. Leijtens B, Koëter M, Kremers $K$, Koëter S. High incidence of postoperative hypothermia in total knee and total hip arthroplasty: a prospective observational study. J Arthroplast. 2013;28(6):895-8. https://doi.org/10.1016/ j.arth.2012.10.006.

11. Long KC, Tanner EJ, Frey M, Leitao MM Jr, Levine DA, Gardner GJ, et al. Intraoperative hypothermia during primary surgical cytoreduction for advanced ovarian cancer: risk factors and associations with postoperative morbidity. Gynecol Oncol. 2013;131(3):525-30. https://doi.org/10.1016/j. ygyno.2013.08.034.

12. Mohib $Y$, Zahid M, Ashraf I, Noordin S. Does hypothermia really contributes to infection in hip and knee arthroplasty? A tertiary care experience. Int J Surg Open. 2017;8:15-7. https://doi.org/10.1016/j.jiso.2017.06.001.

13. Frisch NB, Pepper AM, Rooney E, Silverton C. Intraoperative hypothermia in Total hip and knee arthroplasty. Orthopedics. 2017;40(1):56-63. https://doi. org/10.3928/01477447-20161017-04.

14. Ashraf I, Mohib Y, Hasan O, Malik A, Ahmad K, Noordin S. Surgical site infection surveillance following total knee arthroplasty: Tertiary care hospital experience. Ann Med Surg (Lond). 2018;31:14-6.

15. Li Y, Liang $H$, Feng $Y$. Prevalence and multivariable factors associated with inadvertent intraoperative hypothermia in video-assisted thoracoscopic surgery: a single-center retrospective study. BMC Anesthesiol. 2020;20(1):25. https://doi.org/10.1186/s12871-020-0953-x. 
16. Martin JR, Beahrs TR, Stuhlman CR, Trousdale RT. Complex primary Total knee arthroplasty: Long-term outcomes. J Bone Joint Surg Am. 2016;98(17): 1459-70. https://doi.org/10.2106/JBJS.15.01173.

17. Koh IJ, Kim TK, Chang CB, Cho HJ, In Y. Trends in Use of Total Knee Arthroplasty in Korea From 2001 to 2010. Clin Orthopaed Related Res. 2013; 471(5):1441-50.

18. Scholten R, Leijtens B, Kremers K, Snoeck M, Koëter S. The incidence of mild hypothermia after total knee or hip arthroplasty: a study of 2600 patients. J Orthop. 2018;15(2):408-11. https://doi.org/10.1016/j.jor.2018.03.014.

19. Usmani MA, Zahid M, Ahmad T, Umer M, Hu R, Hashmi PM, et al. Surgical care improvement program and surgical site infections: initiatives to improve outcome in patients with joint replacements in a tertiary care center in Pakistan. IJS Glob Health. 2019;2(2):e05.

20. Raddaoui K, Khedhri W, Zoghlami K, Radhouani M, Trigui E, Kaabachi O Perioperative morbidity in total knee arthroplasty. Pan Afr Med J. 2019:33:233.

21. Qadir I, Shah B, Waqas M, Ahmad U, Javed S, Aziz A. Component alignment in simultaneous bilateral versus unilateral Total knee arthroplasty. Knee Surg Relat Res. 2019;31(1):31-6. https://doi.org/10.5792/ksrr.18.049.

22. Vural F, Çelik B, Deveci Z, Yasak K. Investigation of inadvertent hypothermia incidence and risk factors. Turk J Surg. 2018;34(4):300-5. https://doi.org/10. 5152/turkjsurg.2018.3992.

23. Belayneh T, Gebeyehu A, Abdissa Z. Post-operative hypothermia in surgical patients at University of Gondar Hospital, Ethiopia. J Anesth Clin Res. 2014; 5(11):1-4.

24. Castillo Monzón CG, Candia Arana CA, Marroquín Valz HA, Aguilar Rodríguez F, Benavides Mejía JJ, Alvarez Gómez JA. Temperature management during the perioperative period and frequency of inadvertent hypothermia in a general hospital. Colombian J Anesthesiol. 2013;41(2):97-103.

\section{Publisher's Note}

Springer Nature remains neutral with regard to jurisdictional claims in published maps and institutional affiliations.

Ready to submit your research? Choose BMC and benefit from:

- fast, convenient online submission

- thorough peer review by experienced researchers in your field

- rapid publication on acceptance

- support for research data, including large and complex data types

- gold Open Access which fosters wider collaboration and increased citations

- maximum visibility for your research: over $100 \mathrm{M}$ website views per year

At $\mathrm{BMC}$, research is always in progress.

Learn more biomedcentral.com/submissions 